\title{
Enhancing student understanding of networks using experiential learning
}

\author{
Amy Paros, Michael Taylor and Robert M. Yawson \\ Quinnipiac University, Hamden, Connecticut, USA
}

\begin{abstract}
Purpose - The purpose of this paper is to provide an experiential learning exercise that develops student understanding of social networks within organizations. Understanding these networks can foster complete access to information and inclusive decision-making that translates into career success.

Design/methodology/approach - This experiential learning classroom exercise supports all student learning styles using a puzzle to teach students to apply social network theory toward real-world decisionmaking. This exercise is best used in small and medium-sized classrooms with ideally 15-40 students. This simulation could be used during 50 up through 120 -min class sessions.

Findings - The game-like environment created by this exercise helps extend real-world understanding that may traditionally be lost with a lecture. Components within this simulation provide balanced consideration for many different learning styles. This exercise has been used successfully within a graduate-level leadership and decision-making course in at least ten sessions over 5 years.
\end{abstract}

Practical implications - This is a real-time theory to practice application exercise where an experiential activity is deployed for students to understand the practical implications and application of a theoretical concept.

Social implications - Organizations have internal social networks connecting employees. These connections are how information is dispersed and knowledge is shared. When these networks are understood and effectively used, it can result in more comprehensive problem-solving, valuable collaboration and the maximization of subject matter expertise within the organization.

Originality/value - This is a "how-to" teaching and pedagogical exercise. It is original with the benefit of its flexibility and adaptability in the classroom.

Keywords Social network theory, Experiential learning, Simulation, Organizational behavior, Decision making, Leadership

Paper type General review

\section{Introduction}

"A social network is the set of actors and the set of ties/relationships connecting them" (Venkataramani, Zhou, Wang, Liao \& Shi, 2016, p. 38). An organization's internal social

(C) Amy Paros, Michael Taylor and Robert M. Yawson. Published in Organization Management Journal. Published by Emerald Publishing Limited. This article is published under the Creative Commons Attribution (CC BY 4.0) licence. Anyone may reproduce, distribute, translate and create derivative works of this article (for both commercial and non-commercial purposes), subject to full attribution to the original publication and authors. The full terms of this licence maybe seen at http:// creativecommons.org/licences/by/4.0/legalcode

Declaration of conflicting interests: The authors declare no potential conflicts of interest with respects to the research, authorship, and/or publication of this article.

Funding acknowledgements: This research received no specific grant from any funding agency in the public, commercial or not-for-profit sectors.

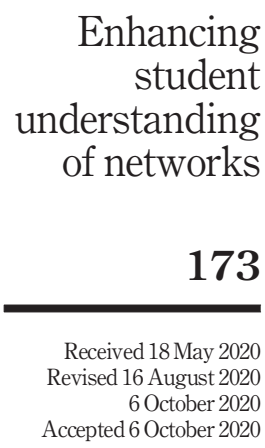

Accepted 6 October 2020 
$\mathrm{OMJ}$

$17,4 / 5$

174

network is the informal social connections by which information travels and knowledge is shared. As work within organizations increasingly relies on the coordination of social networks, leaders and managers need to play an active role in acknowledging, defining and leveraging these networks when making decisions (Cross, Parker, Prusak \& Borgatti, 2001; Cross \& Parker, 2004; Cross, 2005; Bertolotti, Macrì \& Tagliaventi, 2005). When the understanding and utilization of these networks is overlooked it could result in less productive problem solving, stunted collaboration, underutilization of expertise and hidden costs (Granovetter, 1973; Granovetter, 1983; Cross et al., 2001; Cross \& Parker, 2004; Cross, 2005).

Because of the costs associated with poor information dissemination, hiring managers demand universities to deliver learning focused on both critical thinking skills and interpersonal communication within the classroom (Benson \& Dresdow, 2015; Marasi, 2019). Although it is challenging to develop an environment that simulates the organization, business simulations, and experiential learning exercises have been successfully used in classrooms to deliver and reinforce learning. Since most traditional business students lack work experience, faculty commonly use experiential learning scenarios to teach real-world concepts (Wood, 2007). "Learning is a holistic process and results from synergetic interactions with the environment” (Bergsteiner, Avery \& Neumann, 2010, p. 30). The use of games in the classroom allows faculty to demonstrate concepts that are typically only available in a real-world working situation (Surti \& Celani, 2019). Beyond usual lecture or case study methodologies, experiential learning and simulation activities are useful for active learning and deliver the "A-Ha" moments for students and facilitate the bringing of theory to a practice experience (Giraud-Carrier \& Schmidt, 2015; Moretz \& Giapponi, 2019). Additionally, experiential learning exercises are beneficial for delivering learning outcomes that revolve around organizational competencies involving employees (Joardar, Jamro \& Ravi, 2019).

Kolb (1984) delivers an experiential learning theory (ELT) that recognizes the cognitive evolution of knowledge development through experience and engagement. Rather than simply allocating a specific learning style to individual students, Kolb's ELT recognizes the cognitive process associated with the development of knowledge as it progresses and changes as students engage with the learning environment (Bergsteiner et al., 2010). Kolb (1984) depicts the learning experience in terms of four distinct but connected phases. The phases of Kolb's ELT are Concrete Experience (CE) or "feeling" as a student engages in the learning, Reflective Observation (RO), or "watching" as the student reflects on what is being learned. The reflection then supports Abstract Conceptualization (AC) or "thinking" logically about the concepts learned, and Active Experimentation (AE), which is the "doing" and application of learning (Watson, Pelkey, Noyes \& Rodgers, 2019).

An organization's greatest asset is its people, and social relationships and swift coordination among employees are what drive organizational performance and effectiveness. The quality of the social networks and connections employees nurture in their work facilitates organizational learning, cooperation, efficiency, and employee loyalty, among many other positive organizational outcomes (Cross \& Parker, 2004; Bertolotti et al., 2005; Venkataramani et al., 2016). Preparing students to be well equipped to enter the workforce with the theoretical and practical understanding of how organizational social networking is critical for organizational performance is essential. The purpose of this paper is, therefore, to provide an experiential learning exercise that develops student understanding of social networks within organizations and provides students with the skills for more comprehensive problem-solving, valuable collaboration, and the maximization of subject matter expertise within organizations. Developing student capability in social 
networks has been shown to provide students with the skills to distinguish relationships within organizations and use an organization's network to support promotability, career mobility and workplace effectivity (Cross \& Parker, 2004). This puzzle exercise is suitable for undergraduate and graduate students studying organizational behavior, decisionmaking and leadership. Students with internship and/or work experience would gain the most benefit from this activity. This exercise would also be very appropriate for corporate training modules. This classroom simulation of social networks embraces the commonly recognized need for experiential learning in classrooms to engage students in the learning process (Kolb, 1984; Bergsteiner et al., 2010), connect theory and application (Dirksen, 2015), while providing students with workplace advantages (Echkardt \& Wetherbe, 2014).

\section{Theoretical foundations}

Work within organizations does not just take place through formal procedures and documented hierarchies, but also the spiderweb of informal social connections and relationships between employees (Granovetter, 1973, 1983; Cross et al., 2001; Cross, 2005). This spiderweb of informal social connections creates a network by which information travels within an organization. As highly skilled knowledge workers become a competitive advantage, it is more important than ever to understand, navigate and maximize networks within organizations (Cross \& Parker, 2004; Cross, 2005). Also, information is not limited to the knowledge of an individual subject matter expert; however, the community within the organization contributes to the collective information (Stewart, Williams, Smith-Gratto, Black \& Kane, 2011). The intentional application of network theory can be especially important for knowledge transfer and knowledge management within an organization's decision-making process (Cross et al., 2001).

The networks that exist within organizations are based on the connectedness between members, or nodes, of the organization (Cummings \& Cross, 2003; Cote, 2019). The pathways and connections between the nodes within an organization represent how information is dispersed and connectivity within the organization (Kaldis, Koukoravas \& Tjortjis, 2007; Cote, 2019). As defined by Granovetter (1973), the strength of the interpersonal tie or connection between nodes is based on the amount of time and intensity of the relationship. A strong tie between two nodes typically exists when the nodes interact frequently, and information flows well. Weak ties exist when nodes interact less frequently and would typically be defined as outside one's "circle of friends" (Granovetter, 1973). Weak ties are not to be considered less important as they can have a broader reach through networks and extend access to information (Granovetter, 1973, 1983).

As the tendency is to rely on the knowledge within our condensed social network during the decision-making process, it could constrain our ability to leverage knowledge, and weak ties can be a very powerful part of extending one's access to information (Cross et al., 2001). Strong ties tend to create a denser network with less deviation, and there is an increased likelihood that information is consistent, however, reaching through weak ties can help increase access to unique or diverse knowledge (Granovetter, 1983). Weak ties can be "indispensable to individuals' opportunities and to their integration into communities" (Granovetter, 1973, p 1378).

The most significant advantage of understanding the connectedness of social networks within organizations is not how to build strong ties, but the ability to extend into an organization's network to use and manage the flow of information. While it is essential to acknowledge that instances exist in organizations where work silos thrive, the preponderance of the extant literature provides evidence supporting integrated and crossfunctional teams to enhance the capability, effectivity, decision-making, and knowledge 
$\mathrm{OMJ}$

$17,4 / 5$

176

transfer (Fiol, 1996; Kraaijenbrink, 2012; Koohang, Koohang, Paliszkiewicz, Paliszkiewicz, Goluchowski \& Goluchowski, 2017; Lara, Sánchez \& Villalobos, 2019; Wood, Grudzinskas, Ross, Bailey, Gordon, Burton \& Wishart, 2020). An understanding of networks can provide employees with leadership and managerial advantages that could enhance their careers and position them for new job opportunities (Granovetter, 1973; Cross \& Parker, 2004). Businesses have an overwhelming demand for employees who can bring together data and information in a way that promotes sound decision-making (Anderson \& Williams, 2019). Bertolotti et al. (2005) recognize that employees play a role in their social networks stating that organizational groups are "less likely to turn into a coercive form of peer control and will rather be experienced by group members as an enhancement of freedom" when employees are included in the organizational process.

Students, as socially connected participants in the classroom, play an active role in their knowledge creation based on engagement and interaction (Nayar \& Koul, 2020). With student learning success in mind, we considered the learning styles defined by Kolb (1984) when we developed this exercise. Table 1 depicts the alignment between the learning styles defined by Kolb (1984) and elements within this activity. Just as learning preferences contribute to learning outcome success, this exercise works to deviate from a lecture-only style approach and create knowledge from experience (Bergsteiner et al., 2010; Muscat \& Mollicone, 2012; Moretz \& Giapponi, 2019). This activity combines the use of readings, lectures, reflection, discussion, and experience to deliver an all-inclusive and engaging approach (Kolb, 1984; Watson et al., 2019).

\section{Instructions for running the exercise}

"The size of the class may impact the ability for a teacher to practice TC [teacher confirmation]. In order to make students feel endorsed and recognized as valuable, it would be difficult, if not impossible, to do so in a lecture hall filled with over 100 students" (Campbell, Eichhorn, Basch \& Wolf, 2009, p. 459). Additionally, it is helpful for the instructor to know the class and witness in class connections prior to this exercise. With the intent of keeping this experiential activity effective, this exercise is recommended in small and medium-sized classrooms with ideally 15-40 students. The student class size and timing are recommendations based on successful instructor experience within a graduatelevel leadership and decision-making course in at least ten sessions over five years. The optimal timing for this exercise, based on the experience noted above, was for it to be conducted during a 75-min class session. However, it is easy to accommodate various

\begin{tabular}{|c|c|c|}
\hline & $\begin{array}{l}\text { Active Experimentation - AE } \\
\text { (Doing) }\end{array}$ & $\begin{array}{l}\text { Reflective Observation - } \\
\text { RO } \\
\text { (Watching) }\end{array}$ \\
\hline $\begin{array}{l}\text { Concrete } \\
\text { Experience-CE } \\
\text { (Feeling) } \\
\text { Abstract } \\
\text { Conceptualization - } \\
\text { AC } \\
\text { (Thinking) }\end{array}$ & $\begin{array}{l}\text { CE-AE: Accommodating } \\
\text { Building and completing the puzzle } \\
\text { AC-AE: Converging } \\
\text { Debrief on the activity, a mapped network, and full } \\
\text { representation of network by completed puzzle. } \\
\text { Additionally, supported by students drawing their } \\
\text { individual networks }\end{array}$ & $\begin{array}{l}\text { CE-RO: Diverging } \\
\text { Mapping the class network } \\
\text { on the board } \\
\text { AC-RO: Assimilating } \\
\text { Readings }\end{array}$ \\
\hline Source: Kolb (1984) & & \\
\hline
\end{tabular}

Table 1.

Consideration for all Learning Styles

Source: Kolb (1984) 
enrollment levels and session durations. Table 2 provides suggestions for student enrollment and class session durations.

\section{Enhancing student \\ understanding \\ of networks}

Supplies needed for running the exercise (tools for pedagogy)

A puzzle: The puzzle must have at least enough pieces so that each student receives at least one puzzle piece. The puzzle should not have more pieces than twice the student count in the classroom. For example, in a classroom of 20 students, a 24-piece puzzle would be adequate. However, a 48-piece puzzle would be too large and a 16-piece puzzle too small. As an additional example, in a classroom of 35 students, a 48-piece puzzle would be adequate. However, a 75-piece puzzle would be too large and a 24-piece puzzle too small.

A chalkboard or dry erase board: A chalkboard or dry erase board to map the network within the class as the exercise unfolds helps to enhance the active learning through visualization and observation.

\section{Preparation needed prior to class}

Prior to class, assign a network theory reading (Granovetter, 1983; Cummings \& Cross, 2003; Cross et al., 2005) for students to complete in advance of the class. This reading intends to give students awareness of the terminology and idea of organizational networks. This activity also helps those students that prefer preparation before contributing in-class feel ready to join the activity. An additional option for this activity that needs to be done before class would be to write an "S" or "W" representing a strong or weak tie on the back of $10 \%$ $20 \%$ of the puzzle pieces. Students with an "S" on their puzzle piece must join the network

\begin{tabular}{|c|c|c|c|}
\hline $\begin{array}{l}\text { Enrollment } \\
\text { (students) }\end{array}$ & Class duration & Tools for Pedagogy & Recommendations \\
\hline $15-20$ & \multirow[t]{3}{*}{$50-60 \mathrm{~min}$} & $\begin{array}{l}\text { 24-piece puzzle } \\
\text { A dry erase board }\end{array}$ & $\begin{array}{l}\text { Complete the lecture and puzzle exercise during one } \\
\text { class session }\end{array}$ \\
\hline $20-30$ & & $\begin{array}{l}\text { 48-piece puzzle } \\
\text { A dry erase board }\end{array}$ & $\begin{array}{l}\text { Complete the lecture during the class session } \\
\text { preceding the puzzle exercise using two class } \\
\text { sessions in total }\end{array}$ \\
\hline $30-40$ & & $\begin{array}{l}\text { 48-piece puzzle } \\
\text { A dry erase board }\end{array}$ & $\begin{array}{l}\text { Complete the lecture during the class session } \\
\text { preceding the puzzle exercise and be prepared to } \\
\text { extend the puzzle exercise to an additional session } \\
\text { using three class sessions in total }\end{array}$ \\
\hline $15-20$ & \multirow[t]{3}{*}{$60-75 \mathrm{~min}$} & $\begin{array}{l}\text { 24-piece puzzle } \\
\text { A dry erase board }\end{array}$ & $\begin{array}{l}\text { Complete the lecture and puzzle exercise during one } \\
\text { class session }\end{array}$ \\
\hline $20-30$ & & $\begin{array}{l}\text { 48-piece puzzle } \\
\text { A dry erase board }\end{array}$ & \\
\hline $30-40$ & & $\begin{array}{l}\text { 48-piece puzzle } \\
\text { A dry erase board }\end{array}$ & $\begin{array}{l}\text { Complete the lecture during the class session } \\
\text { preceding the puzzle exercise using two class } \\
\text { sessions in total }\end{array}$ \\
\hline $15-20$ & $75-120+\min$ & $\begin{array}{l}\text { 24-piece puzzle } \\
\text { A dry erase board }\end{array}$ & $\begin{array}{l}\text { Complete the lecture and puzzle exercise during one } \\
\text { class session }\end{array}$ \\
\hline $20-30$ & & $\begin{array}{l}\text { 48-piece puzzle } \\
\text { A dry erase board }\end{array}$ & \\
\hline $30-40$ & & $\begin{array}{l}\text { 48-piece puzzle } \\
\text { A dry erase board }\end{array}$ & \\
\hline
\end{tabular}

Table 2.

Student enrollment and class session duration recommendations 
$\mathrm{OMJ}$

$17,4 / 5$

by means of a strong tie, and students with a "W" on their puzzle piece must join the network by means of a weak tie.

\section{Exercise during class}

Open class with a short lecture-style recap of the main points of networks within organizations. During this lecture, discuss nodes, strong and weak ties, and the importance of information flow within networks. Be sure to convey the importance of the connectedness and reach of the network over the nature of the relationship as a strong or weak tie. This lecture should take about $15 \mathrm{~min}$ and give students the notion that a more connected network has better information flow. At the close of the lecture, pass out all the pieces to the puzzle, ensuring each student has at least one puzzle piece. Once all the puzzle pieces are handed out, a student will be chosen to become the first node in the classroom's social network. He or she will bring their puzzle piece up to the designated space for building the puzzle. The student's name will be added to the center of the board as the first node documented in this network. Next, ask the student if he or she has any strong ties within the classroom.

Strong ties are easily identified when you ask the students if they have called or texted one another recently. As students who have strong ties are identified, they approach the front of the classroom, bring their puzzle piece up to the designated space for building the puzzle, and begin to work on building the puzzle. The name of every student who is identified will be added to the board as a node and the strong or weak ties for each student documented within the network. All strong and weak ties between the students identified on the board are mapped before moving on to include the next student. You would then repeat the above activities until all the student nodes sharing strong ties with one another have been mapped into the network and the applicable puzzle pieces added to the puzzle. After all the strong ties are exhausted and illustrated on the board, acknowledge the state of the puzzle. The puzzle will likely be partially built. The puzzle represents a visual of the decision-making information collected. As engaging strong ties is more natural, you should include those nodes in decision-making easily. However, the puzzle visually depicts the major gaps that could exist if students do not learn to extend themselves by leveraging weak ties. At this point, ask the students (nodes) already documented in the network to identify the weak ties they have with the students remaining in the classroom.

Weak ties are easily identified in the class when you ask the students if they could walk up to another student and ask a question about class. Many times, student weak tie connections are facilitated by group work in prior courses, social activities or other school experiences. You may eventually allow students to use this class or yourself as a weak tie pathway within the network, but keep this for bringing in remaining students as needed to avoid diluting the learning and becoming repetitive. As weak ties are identified, they approach the front of the classroom, bring their puzzle piece up to the designated space for building the puzzle, and join those working on building the puzzle. The name of every student who is identified will be added to the board as a node and the strong or weak ties for this student mapped within the network depicted on the board. All strong and weak ties between the students identified on the board are mapped before moving on to include the next student. You would then repeat the above activities until all the students within the class are brought into the network, and the applicable puzzle pieces added to complete the puzzle. Figure 1 shares examples of the board when drawing the classroom network. As students are added to the social network drawn on the board, be sure students reflect on the development of the puzzle and its stage of completeness. This activity should take between 


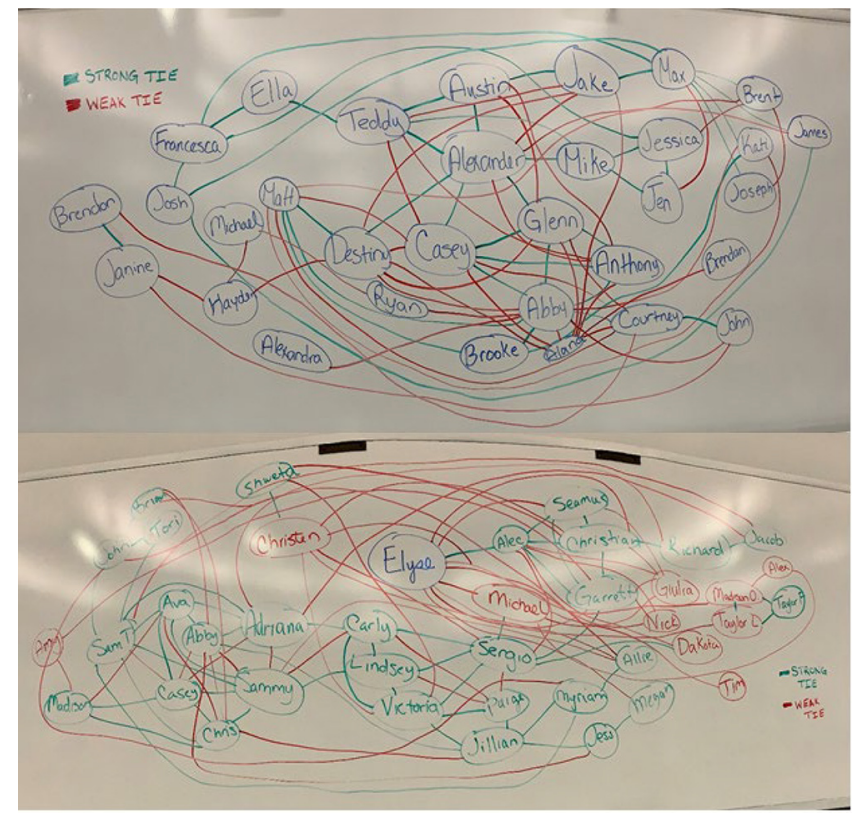

\section{Enhancing student understanding of networks}

179

Figure 1.

Examples of the board when drawing the classroom network

one and one and a half minutes per student in the class. For example, a class of 30 students could take between 30 and 45 min to complete.

\section{Note on students' mental health}

Despite the high likelihood that all students in the classroom will be documented as a node in the network, there is always a possibility that one or more students are left without any identified strong or weak ties to any other class members. These students are now outside the established network and may experience feelings of rejection or absence of belonging. This presents some cause for concern about their mental health and self-esteem. However, a meta-analysis of studies related to interpersonal rejection and ostracism indicated that the result of a single instance of rejection is typically a neutral emotional state without a negative impact on self-esteem (Blackhart et al., 2009). This indicates that students outside the network should not suffer psychologically due to a single exclusion. Furthermore, instances of acceptance and inclusivity, like those fostered by this role-play, can increase positive moods and self-esteem (Blackhart et al., 2009). By adjusting the classroom discussion and exercise debrief, you can find ways to incorporate the excluded students into the network to promote feelings of acceptance, which will mitigate the initial feeling of rejection.

Running this exercise several weeks into the course, rather than immediately at the beginning, will allow the instructor time to observe where the student network hubs exist, as well as consider the potential for outliers who may be a challenge to tie into the network example. If you encounter this scenario, you should first attempt to expand these students' perceptions of where they may have strong or weak ties with students in the documented network. This could include potential weak ties they had not previously considered, such as on- or off-campus jobs, involvement in clubs, student government, Greek Life or even their 
$\mathrm{OMJ}$

$17,4 / 5$

180

housing assignments. Additionally, many students may take more than one course of study at a time and could have weak ties because of other course projects, classes, or team groupings. Assuming no new strong or weak ties have been discovered, you might also want to talk in more depth about how strong and weak ties are developed in organizations over time, for example, when new employees are hired. Although the general instructions for the exercise tell the students not to use your course as a source of strong or weak ties, you now have the opportunity to show how an excluded student's enrollment in the course has helped to develop new ties and add another node to the network. Keeping the tone for the inclusion of this new evolution in the network as positive and inclusive could provide an opportunity to increase the student's self-esteem (Blackhart et al., 2009).

\section{Debriefing the exercise}

This exercise is intended for students to recognize the connectivity and stretch of networks so that they can engage in their organizations more effectively. This network simulation teaches students about various connections between contributing nodes of information within an organization and helps them to recognize how to use strong and weak ties in an organization. During this exercise, students will watch as the classroom's social network is laid out on the board so that they can then mirror the process and illustrate their own networks. Throughout this activity and again during the debrief, discussions about the types of ties and the reach of the spiderweb of connections that unfolds encourage students to contemplate social network theory in terms of how information is used to make decisions within an organization. Finally, the act of building and completing the puzzle represents the utilization of an organization's network to engage all functions and expertise to enhance extending into those weak ties to problemsolving, collect complete information and deliver a comprehensive product, solution or other initiatives.

This exercise can be debriefed in terms of leadership, management, organizational behavior, decision-making or career management. Debriefing this activity helps students extract the value from the exercise and conceptualize how it translates into the workplace. Immediately following the completion of the puzzle, ask students to reflect on the experience. While students share their experiences, connect their observations to organizational behavior, information management, leadership, and decision-making. Some questions to start the debrief include:

- What surprised you about the connections within our classroom network?

- How does this translate to your working view of an organization?

- How were we able to complete the puzzle? What does the completed puzzle represent, and why is it important?

- What is the advantage of having an extensive network leveraging weak ties? How can you ensure you engage weak ties in the decision-making and problem-solving process? What role do strong ties play in an organization?

- How can you use this understanding of networks to close knowledge gaps?

The discussion can be followed up with an individual exercise where students map out their own personal networks, including the strong and weak ties among the individual nodes. This individual network mapping can be done in class or as homework reflection to cement the learning outcomes. 


\section{Conclusion}

Student feedback for this activity has been positive and could suggest that the use of an experiential exercise makes learning real business concepts more digestible. Some students shared that "Before the puzzle activity, I did not understand what the reading meant by a strong or weak tie," "The exercise helped to visualize the connectedness of hubs and nodes," and "I could use network theory to understand how to get work done." The concepts delivered in this social network exercise will translate directly into a student's college to career success.

This exercise has been used successfully within a graduate-level leadership and decisionmaking course in at least ten sessions over five years. In using this exercise in a course, students can be further asked to apply their understanding of social networks as a component within a final written course assignment. A piece of this final reflection may include individual consideration for how the student could use his or her personal social network to find a job postgraduation. In our school, this final reflective assignment is used as an assessment artifact for assessing assurance of learning as part of the requirements for maintaining accreditation through the Association to Advance Collegiate Schools of Business (AACSB).

\section{Implications of the study and recommendations for future research}

An organization's internal social network governs how information and knowledge travels and is shared throughout the organization. As work continues to rely heavily on the coordination of individual hubs within the social networks that make up our businesses, a proactive awareness for and ability to leverage these networks when making decisions will benefit leaders (Cross, Parker, Prusak \& Borgatti, 2001; Cross \& Parker, 2004; Cross, 2005). If social networks are dismissed in organizations, it could result in less productive problem-solving, stunted collaboration, underutilization of expertise, and unknown costs (Granovetter, 1973, 1983; Cross et al., 2001; Cross $\&$ Parker, 2004; Cross, 2005). An exercise like the one included here, meets hiring managers needs to boost learning centered on critical thinking skills and communication (Benson \& Dresdow, 2015; Marasi, 2019) while enabling a workforce awareness for using social networks to promote business success. Delivering capable students to the workforce with the theoretical and practical understanding of organizational social networks can support organizational performance with employees more prepared to engage in comprehensive problem-solving, effective collaboration and understanding of subject matter expert knowledge within their organizations.

There are exciting possibilities for future research in relation to this study, including an understanding of the influence student experience in organizational social networks has within the context of learning retention and previous student work experience, internship hiring rates, or type of work preferences. Future research could also include a survey or experimental design that assesses the benefit social network knowledge has for students once they graduate and begin employment. Remote working was on the increase before COVID-19, and a post-COVID-19 scenario of fully established telecommuting society necessitates the re-orientation of social network research and practice (Yawson, 2020). "Organizations will have to determine new ways of building social capital and social networking and how to maintain cohesion without the benefit of informal coffee, lunch, or corridor chats" (Yawson, 2020, p. 410). Future applications could include developing an online simulation exercise for both on-ground and virtual classrooms to simulate the remote working environment.

\section{References}

Anderson, J. S. \& Williams, S. K. (2019). Turning data into better decision-making: Asking questions, collecting and analyzing data in a personal analytics project. Decision Sciences Journal of Innovative Education, 17(2), 126-145, doi: 10.1111/dsji.12173.
Enhancing student understanding of networks

181 
$\mathrm{OMJ}$

$17,4 / 5$

Benson, J. \& Dresdow, S. (2015). Design for thinking: Engagement in an innovation project. Decision Sciences Journal of Innovative Education, 13(3), 377-410, doi: 10.1111/dsji.12069.

Bergsteiner, H., Avery, G. C., \& Neumann, R. (2010). Kolb's experiential learning model: Critique from a modelling perspective. Studies in Continuing Education, 32(1), 29-46, doi: 10.1080/ 01580370903534355.

Bertolotti, F., Macrì, D. M., \& Tagliaventi, M. R. (2005). Spontaneous self-managing practices in groups: Evidence from the field. Journal of Management Inquiry, 14(4), 366-384, doi: 10.1177/ 1056492605280224.

Blackhart, G. C., Nelson, B. C., Knowles, M. L., \& Baumeister, R. F. (2009). Rejection elicits emotional reactions but neither causes immediate distress nor lowers self-esteem: A meta-analytic review of 192 studies on social exclusion. Personality and Social Psychology Review, 13(4), 269-309. https://doi.org/10.1177/1088868309346065, doi: 10.1177/1088868309346065.

Campbell, L. C., Eichhorn, K. C., Basch, C., \& Wolf, R. (2009). Exploring the relationship between teacher confirmation, gender, and student effort in the college classroom. Human Communication, 12(4), 447-464.

Cote, R. (2019). The evolution of social network theory: Perceived impact on developing networking relationships. American Journal of Management, 19(3), 19-34.

Cross, R., Parker, A., Prusak, L., \& Borgatti, S. P. (2001). Knowing what we know: Supporting knowledge creation and sharing in social networks. Organizational Dynamics, 30(2), 100-120. doi: 10.1016/S0090-2616(01)00046-8.

Cross, R. \& Parker, A. (2004). The hidden power of social networks: Understanding how work really gets done in organizations, Boston, MA: Harvard Business Review Press.

Cross, R. Liedtka, J. \& Weiss, (2005). A practical guide to social networks. Harvard Business Review. Retrieved from https://hbr.org/2005/03/a-practical-guide-to-social-networks

Cummings, J. N. \& Cross, R. (2003). Structural properties of work groups and their consequences for performance. Social Networks, 25(3), 197-210, doi: 10.1016/S0378-8733(02)00049-7.

Dirksen, J. (2015). Design for how people learn, 2nd Ed, Berkley, CA: New Riders.

Echkardt, J. \&. \& Wetherbe, J. (2014). Making business school research more relevant. Harvard Business Review. Retrieved from http:/hbr.org/2014/12/making-business-school-research-more-relevant

Fiol, M. (1996). Squeezing harder doesn't always work: Continuing the search for consistency in innovation research. Academy of Management Review, 21(4), 1012-1021. doi: 10.5465/amr.1996.15868543.

Giraud-Carrier, F. C. \& Schmidt, G. M. (2015). Learning in the fast lane: The freeway game: Learning in the fast lane. Decision Sciences Journal of Innovative Education, 13(3), 273, doi: 10.1111/dsji.12068. 287-

Granovetter, M. S. (1973). The strength of weak ties. American Journal of Sociology, 78(6), 1360-1380, doi: $10.1086 / 225469$.

Granovetter, M. (1983). The strength of weak ties: A network theory revisited. Sociological Theory, 1, 201-233, doi: 10.2307/202051.

Joardar, A., Jamro, K., \& Ravi, R. (2019). The business meeting: A cross-cultural experiential learning activity. Organization Management Journal, 16(4), 338-349, doi: 10.1080/15416518.2019.1663143.

Kaldis, E., Koukoravas, K., \& Tjortjis, C. (2007). Reengineering academic teams toward a network organizational structure. Decision Sciences Journal of Innovative Education, 5(2), 245-266, doi: 10.1111/j.1540-4609.2007.00140.x.

Kolb, D. A. (1984). Experiential learning: Experience as the source of learning and development, Englewood Cliffs, NJ: Prentice-Hall.

Koohang, A., Koohang, A., Paliszkiewicz, J., Paliszkiewicz, J., Goluchowski, J., \& Goluchowski, J. (2017). The impact of leadership on trust, knowledge management, and organisational performance: A research model. Industrial Management \& Data Systems, 117(3), 521-537, doi: 10.1108/IMDS-022016-0072. 
Kraaijenbrink, J. (2012). Integrating knowledge and knowledge processes: a critical incident study of product development projects. Journal of Product Innovation Management, 29(6), 1082-1096. doi: 10.1111/j.1540-5885.2012.00953.x.

Lara, P., Sánchez, M., \& Villalobos, J. (2019). OT modeling: the enterprise beyond IT. Business \& Information Systems Engineering, 61(4), 399-411, doi: 10.1007/s12599-018-0543-3.

Enhancing student

understanding of networks

Marasi, S. (2019). Team-building: Developing teamwork skills in college students using experiential activities in a classroom setting. Organization Management Journal, 16(4), 324-337, doi: 10.1080/ 15416518.2019.1662761.

Moretz, J. \& Giapponi, C. C. (2019). Stakeholders and business strategy: a role-play negotiation themed exercise. Organization Management Journal, 16(1), 14-26, doi: 10.1080/15416518.2019.1573130.

Muscat, M. \& Mollicone, P. (2012). Using Kolb's learning cycle to enhance the teaching and learning of mechanics of materials. International Journal of Mechanical Engineering Education, 40(1), 66-78, doi: 10.7227/IJMEE.40.1.10.

Nayar, B. \& Koul, S. (2020). The journey from recall to knowledge: A study of two factors - structured doodling and note-taking on a student's recall ability International Journal of Educational Management, 34(1), 127-138, doi: 10.1108/IJEM-01-2019-0002.

Stewart, A. C., Williams, J., Smith-Gratto, K., Black, S. S., \& Kane, B. T. (2011). Examining the impact of pedagogy on student application of learning: Acquiring, sharing, and using knowledge for organizational decision-making: Examining impact of pedagogy on student application of learning. Decision Sciences Journal of Innovative Education, 9(1), 3-26, doi: 10.1111/j.1540-4609.2010.00288.x.

Surti, C. \& Celani, A. (2019). Newsvendor game: A behavioral exercise in decision-making under risk: Newsvendor game decision. Decision Sciences Journal of Innovative Education, 17(4), 324-343, doi: $10.1111 /$ dsji.12194.

Venkataramani, V., Zhou, L., Wang, M., Liao, H., \& Shi, J. (2016). Social networks and employee voice: The influence of team members' and team leaders' social network positions on employee voice. Organizational Behavior and Human Decision Processes, 132, 37-48, doi: 10.1016/j.obhdp.2015.12.001.

Watson, M. K., Pelkey, J., Noyes, C., \& Rodgers, M. O. (2019). Using Kolb's learning cycle to improve student sustainability knowledge. Sustainability, 11(17), 4602, doi: 10.3390/su11174602.

Wood, S. C. (2007). Online games to teach operations. INFORMS Transactions on Education, 8(1), 3-9, doi: 10.1287/ited.8.1.3.

Wood, A., Grudzinskas, K., Ross, J., Bailey, S., Gordon, G., Burton, C., \& Wishart, L. (2020). Strengthening teamwork capability in allied health: Implementation of a team development program in a metropolitan health service. Australian Health Review, 44(3), 443-450, doi: 10.1071/AH19055.

Yawson, R. (2020). Strategic flexibility analysis of HRD research and practice post COVID-19 pandemic. Human Resource Development International, 23(4), 406-417. Retrieved from https:// doi.org/10.1080/13678868.2020.1779169 doi: 10.1080/13678868.2020.1779169.

\section{Further reading}

Aral, S. (2016). The future of weak ties. American Journal of Sociology, 121(6), doi: 10.1086/686293.

\section{Corresponding author}

Amy Paros can be contacted at: amy.paros@quinnipiac.edu

For instructions on how to order reprints of this article, please visit our website:

www.emeraldgrouppublishing.com/licensing/reprints.htm

Or contact us for further details: permissions@emeraldinsight.com 